\title{
Effect of active fraction isolated from the leaf extract of Dregea volubilis [Linn.] Benth. on plasma glucose concentration and lipid profile in streptozotocin-induced diabetic rats
}

\author{
Venkatesan Natarajan ${ }^{*}$ and Anton Smith Arul Gnana Dhas
}

\begin{abstract}
Objective: The objective of the present study was to evaluate the effect of active fraction from Dregea volubilis [Linn.] Benth leaves on serum glucose and lipid profile in normal and diabetic rats.

Materials and methods: Diabetes was induced by streptozotocin in wistar rats. Petroleum ether, ethyl acetate, and ethanol extracts of Dregea volubilis [Linn.] Benth leaves were administered orally at a dose of $200 \mathrm{mg} / \mathrm{kg}$, p.o.

Metformin was used as standard Anti-diabetic drug (50 mg/kg, p.o). The extract showing for higher Anti-diabetic activity was subjected to column chromatography that led to isolation of an active fraction, which was given trivial name Dv-1. Dv-1 (100 mg/kg, p.o.) was studied for its hypoglycemic and hypolipidemic potential.

Results: Ethanol extract was found to lower the Fasting blood glucose (FBG) level significantly $(p<0.05)$ in diabetic rats. Dv-1 caused a significant $(p<0.05)$ reduction in FBG level. Additionally it also caused reduction in cholesterol, triglyceride levels and improvement in the HDL level in diabetic rats.

Conclusion: Reduction in the FBG, cholesterol, triglyceride levels and improvement in the HDL by DV-1 indicates that Dv-1 has Anti-diabetic activity along with anti hyperlipidemic efficacy and provides a scientific rationale for the use as an Anti-diabetic agent.
\end{abstract}

Keywords: Blood glucose; Hexadecenoic acid; Dregea volubilis [Linn.] Benth; Lipid profile

\section{Introduction}

Diabetes is a complex and a multivarious group of disorders that disturbs the metabolism of carbohydrates, fat and protein (Kahn et al. 1991) characterized by increased fasting and postprandial blood sugar levels. Diabetes mellitus is classified into two major subtypes: type I (insulin dependent diabetes mellitus, IDDM) and type II (non-insulin dependent diabetes mellitus, NIDDM). IDDM or juvenile-onset diabetes results from a cellular mediated autoimmune destruction of the $\beta$-cells of the pancreas (Aikinson et al. 1994). However, NIDDM or adult-onset diabetes results from the development of insulin resistance and the affected individuals usually have insulin deficiency (Takeshi et al. 2002). Type II diabetes

\footnotetext{
* Correspondence: venkatcology@gmail.com

Department of Pharmacy, Annamalai University, Annamalai Nagar, Tamil nadu 608 002, India
}

\section{Springer}

(c) 2013 Natarajan and Arul Gnana Dhas; licensee Springer. This is an Open Access article distributed under the terms of the Creative Commons Attribution License (http://creativecommons.org/licenses/by/2.0), which permits unrestricted use,

distribution, and reproduction in any medium, provided the original work is properly cited. of the diabetic population. In 1995 it was estimated that around 135 million people were affected from this condition and it was expected to affect 300 million by the year 2025 (King et al. 1998). Management of diabetes without any side effect is still a challenge to the medical community. Several drugs such as biguanides, sulfonylurea and thiazolidenediones are presently available to treat the diabetes mellitus (De-Fronzo et al. 1997). The use of these drugs is restricted by their pharmacokinetic properties, secondary failure rates and accompanying side effects (Donath et al. 2006). Thus searching for a new class of compounds is essential to overcome diabetic problems ultimately leading to continuous search for alternative drugs (Hansotia et al. 2005). The medicinal plants may provide the useful source of new oral hypoglycemic compounds for the development of 
pharmaceutical entities or as dietary adjunct to existing therapies (Pepato et al. 2005). Furthermore, after the recommendation made by $\mathrm{WHO}$ on diabetes mellitus, investigation on hypoglycemic agents from medicinal plants have become more important. The ethnobotanical information reports state that about 800 plants may possess Anti-diabetic potential (Grover et al. 2004). Recently the medicinal values of various plant extracts have been studied by many scientists in the field of diabetic research (Jain et al. 2010). The rational design of novel drugs from traditional medicine offers new prospects in modern healthcare. More than 800 plants are used as traditional remedies for the treatment of diabetes throughout the world (Kavishankar et al. 2011). Dregea volubilis [Linn.] Benth belongs to family Asclepiadaceae is widely used in Indian traditional medicines and the leaf paste is used to treat rheumatic pain, cough, fever and severe cold (Rajadurai et al. 2009). Leaf paste is taken along with pepper to treat dyspepsia (Pandikumar et al. 2007); bark paste mixed with hot milk is used internally for treating urinary infections (Silija et al. 2008). The plant is being used very specifically in the indigenous systems of medicine such as Ayurveda, Siddha and Unani. The present study was planned to compare the blood glucose-lowering activity of different extracts/fractions of Dregea volubilis in order to isolate the active principle responsible for the Anti-diabetic activity of the plant. Further study was carried out to evaluate the Anti-diabetic and hypolipidemic effects of active principle (Dv-1) from Dregea volubilis leaf extract on normal and diabetic rats.

\section{Methods}

\section{Drugs and chemicals}

Streptozotocin (STZ) was purchased from Sigma aldrich, Bangalore, India. Standard Anti-diabetic drug Metformin was obtained from Actavis pharmaceutical, Chennai, India. Analytical grade of chemicals, including various organic solvents (petroleum ether, ethyl acetate, chloroform, ethanol and methanol) from S.D. Fine Chemicals, India, were used for the extraction and the phytochemical study of the constituents.

\section{Preparation of different plant extracts}

Dregea volubilis leaves were collected from the forest of kalakatu, Tirunelveli District, India. Taxonomic identification was made from botanical survey of medicinal plants, Siddha Unit, Government of India, Palayamkottai authenticated by Chelladurai Botanist. A voucher specimen No (CCRAS-167/2011). Fresh plant leaves were shade dried at room temperature, ground into fine powder and stored in airtight containers. Then extracted (amount $500 \mathrm{~g}$ ) with solvents of increasing polarity such as petroleum ether, ethyl acetate, and ethanol, for
72 hours with each solvent, by continuous hot extraction using the soxhlet apparatus at a temperature of $60^{\circ} \mathrm{C}$. The extracts were concentrated under reduced pressure using a rotary evaporator to constant weight. The extracts were collected and preserved in a desiccator until used for further studies. The percentage yields were $10.81 \%$ in petroleum ether, $11.36 \%$ in ethyl acetate and $12.13 \%$ in ethanol.

\section{Acute toxicity study}

Acute toxicity study was performed according to OECD423 guidelines. Albino rats $(n=6)$ of either sex selected by random sampling technique were employed in this study. The animals were fasted for $4 \mathrm{~h}$ with free access to water only. The various extract of Dregea volubilis suspended in normal saline: tween 80 (95:5) which was administered orally at a dose of $5 \mathrm{mg} / \mathrm{kg}$ initially and mortality was observed for 3 days. The mortality was not observed, the procedure was then repeated with higher doses such as 50, 300, 1000, and $2000 \mathrm{mg} / \mathrm{kg}$. The mortality was observed in $5 / 6$ or $6 / 6$ animals when administered with the dose of $2000 \mathrm{mg} / \mathrm{kg}$ and then the dose administered was considered as toxic dose. However, the mortality was observed in less than four rats, out of six animals then the same dose was repeated again to confirm the toxic effect.

\section{Animals}

Male wistar rats each weighing 180-220 g was obtained from Raja Muthiah Medical College and Hospital (RMM $\mathrm{CH}$ ) in Annamalai University at Chidambaram, Tamil nadu, India. The guidelines of the Committee for the purpose of control and supervision of experiments on animals (CPCSEA) of the Government of India were followed and prior permission was granted from the Institutional animal ethics committee (NO.842/CPCSEA). Rodent laboratory chow was access and water $\mathrm{ad}$ libitum, and rats were maintained on a 12 hour light/ dark cycle in a temperature regulated room $\left(20-25^{\circ} \mathrm{C}\right)$ during the experimental procedures.

\section{Induction of diabetes}

The fasted rats (Sriplang et al. 2007) were injected intravenously with $50 \mathrm{mg} / \mathrm{kg}$ of STZ. The STZ was freshly dissolved in citrate buffer $(0.01 \mathrm{M}, \mathrm{pH} 4.5)$ and kept on ice prior to use. One week after STZ administration, the rats with FBG concentrations of over $150 \mathrm{mg} / \mathrm{dl}$ were considered to be diabetic and were used in the experiment.

\section{The oral glucose tolerance test (OGTT) in normal and STZ induced diabetic rats}

After an overnight fasting, normal and diabetic rats were divided into five groups each with 6 rats in each group. Group I rats received $1 \mathrm{ml}$ of distilled water only. 
Table 1 Effect of different Dregea volubilis [Linn.] Benth leaf extracts on plasma glucose concentration in normal rats

\begin{tabular}{|c|c|c|c|c|c|c|}
\hline \multirow[t]{2}{*}{ Treatments } & \multicolumn{6}{|c|}{ Time (min) before and after glucose administration } \\
\hline & -30 & 0 & 30 & 90 & 150 & 210 \\
\hline Normal animals & $78.4 \pm 3.1$ & $81.6 \pm 3.1$ & $173.2 \pm 1.6$ & $136.4 \pm 1.8$ & $99.8 \pm 5.8$ & $88.2 \pm 2.4$ \\
\hline Petroleum ether $(200 \mathrm{mg} / \mathrm{kg})$ & $75.7 \pm 3.2$ & $70.5 \pm 4.9$ & $175.6 \pm 2.4$ & $114.6 \pm 3.4$ & $106.7 \pm 5.9$ & $96.1 \pm 1.4$ \\
\hline Ethyl acetate $(200 \mathrm{mg} / \mathrm{kg})$ & $79.4 \pm 2.9$ & $71.4 \pm 4.7$ & $142.3 \pm 1.8$ & $117.4 \pm 2.4$ & $102.4 \pm 3.4$ & $94.5 \pm 4.8$ \\
\hline Ethanol $(200 \mathrm{mg} / \mathrm{kg})$ & $76.4 \pm 2.6$ & $72.4 \pm 2.6$ & $130.2 \pm 1.9$ & $99.1 \pm 2.9$ & $92.6 \pm 2.3^{*}$ & $84.9 \pm 3.6^{*}$ \\
\hline Metformin $(50 \mathrm{mg} / \mathrm{kg})$ & $77.9 \pm 3.1$ & $81.8 \pm 2.3$ & $124.1 \pm 2.5$ & $96.4 \pm 3.2$ & $89.9 \pm 3.1^{*}$ & $79.8 \pm 2.8^{*}$ \\
\hline
\end{tabular}

Data are expressed as mean \pm SEM. $n=6$ rats per group. ${ }^{*} p<0.05$, compared to normal control group.

Groups II - IV rats received various extracts of Dregea volubilis orally at $200 \mathrm{mg} / \mathrm{kg}$ respectively. Group V rats received $50 \mathrm{mg} / \mathrm{kg}$ Metformin. Glucose (3 g/kg) was administered orally to each rat $30 \mathrm{~min}$ later. Blood samples $(0.5-0.6 \mathrm{ml})$ were collected from the tail vein in chilled heparinized tubes at $-30,0,30,90,120$ and $210 \mathrm{~min}$ for the estimation of blood glucose level. After centrifugation $(2000 \times \mathrm{g})$, plasma was removed and stored at $-20^{\circ} \mathrm{C}$. The plasma glucose concentrations were measured by the method of glucose oxidase - peroxides using Span diagnostic kits. After the pharmacological screening, it was found that among all the extracts, ethanolic extract showed a maximum decrease in FBG level. Hence, it was subjected to column chromatography and active principle was isolated.

\section{Isolation of active principle from ethanolic extract of Dregea volubilis leaf}

Ethanolic extract of Dregea volubilis (10 g) was subjected to chromatography over a column of silica gel (60-120 mesh). The column was eluted successively with petroleum ether, petroleum ether - chloroform mixture, chloroform - methanol mixture in different proportion in the order of increasing polarity. Fractions with same $\mathrm{Rf}$ values on TLC were combined and evaporated to dryness under reduced pressure. The major active fraction (2.5 g) was obtained after elution with chloroform: methanol (70:30) and was further purified by chromatography over a column of silica gel (100-200) resulting in a yellow amorphous solid (2.0 g) after eluting with chloroform: methanol (75:25). An isolated fraction has been confirmed by GC-MS analysis which was given a trivial name Dv-1.

\section{Effect of DV-1 on FBG and lipid profile in diabetic rats}

Normal and diabetic rats were divided into four groups with six rats in each group. Group I-normal rats received $1 \mathrm{ml}$ of distilled water. Group II-diabetic rats received $1 \mathrm{ml}$ of distilled water. Group III-diabetic rats received $100 \mathrm{mg} / \mathrm{kg}$ DV-1. Group IV-diabetic rats received $50 \mathrm{mg} / \mathrm{kg}$ Metformin. All the groups were treated orally for 21 days. At the end of the experimental period, the animals were fasted overnight for 8 hours and blood sample was taken from the retro orbital plexus under mild ether anaesthesia. Plasma was separated out and FBG level was measured by the method of glucose oxidase-peroxides using Span Diagnostic kits. Cholesterol level was determined by the enzymatic method (Masana et al. 2012), triglyceride by the enzymatic colorimetric method (Heber et al. 2013) and HDL by the phosphotungstate method (Tripathi et al. 2012) using span diagnostic kits in chemical under Methods.

\section{Identification of isolated fraction}

Interpretation of GC-MS (Perkin-Elmer) was conducted using the database of National Institute Standard and Technology (NIST) having more than 62,000 patterns. The spectrum of the unknown components was compared with the spectrum of known components stored in the NIST library. The name, molecular weight, and structure of the components of the test materials were ascertained.

Table 2 Effect of different Dregea volubilis [Linn.] Benth leaf extracts on plasma glucose concentration in diabetic rats

\begin{tabular}{|c|c|c|c|c|c|c|}
\hline \multirow[t]{2}{*}{ Treatments } & \multicolumn{6}{|c|}{ Time (min) before and after glucose administration } \\
\hline & -30 & 0 & 30 & 90 & 150 & 210 \\
\hline Normal animals & $174.8 \pm 5.6$ & $167.8 \pm 3.1$ & $234.1 \pm 2.4$ & $225.3 \pm 1.9$ & $188.3 \pm 1.8$ & $184.2 \pm 2.4$ \\
\hline Petroleum ether $(200 \mathrm{mg} / \mathrm{kg})$ & $148.5 \pm 3.2$ & $146.7 \pm 4.9$ & $237.6 \pm 2.4$ & $221.6 \pm 3.4$ & $173.7 \pm 5.9$ & $168.1 \pm 1.4$ \\
\hline Ethyl acetate $(200 \mathrm{mg} / \mathrm{kg})$ & $165.9 \pm 2.9$ & $153.1 \pm 4.7$ & $229.3 \pm 1.8$ & $195.4 \pm 2.4$ & $172.4 \pm 3.4$ & $164.5 \pm 4.8$ \\
\hline Ethanol $(200 \mathrm{mg} / \mathrm{kg})$ & $170.4 \pm 2.6$ & $164.4 \pm 2.6$ & $224.2 \pm 1.9$ & $180.1 \pm 2.9$ & $142.6 \pm 2.3^{*}$ & $96.9 \pm 3.6^{*}$ \\
\hline Metformin (50 mg/kg) & $171.9 \pm 3.1$ & $170.8 \pm 2.3$ & $226.1 \pm 2.5$ & $143.4 \pm 3.2^{*}$ & $138.9 \pm 3.1^{*}$ & $79.8 \pm 2.8^{*}$ \\
\hline
\end{tabular}

Data are expressed as mean \pm SEM. $n=6$ rats per group. ${ }^{*} p<0.05$, compared to diabetic control group. 


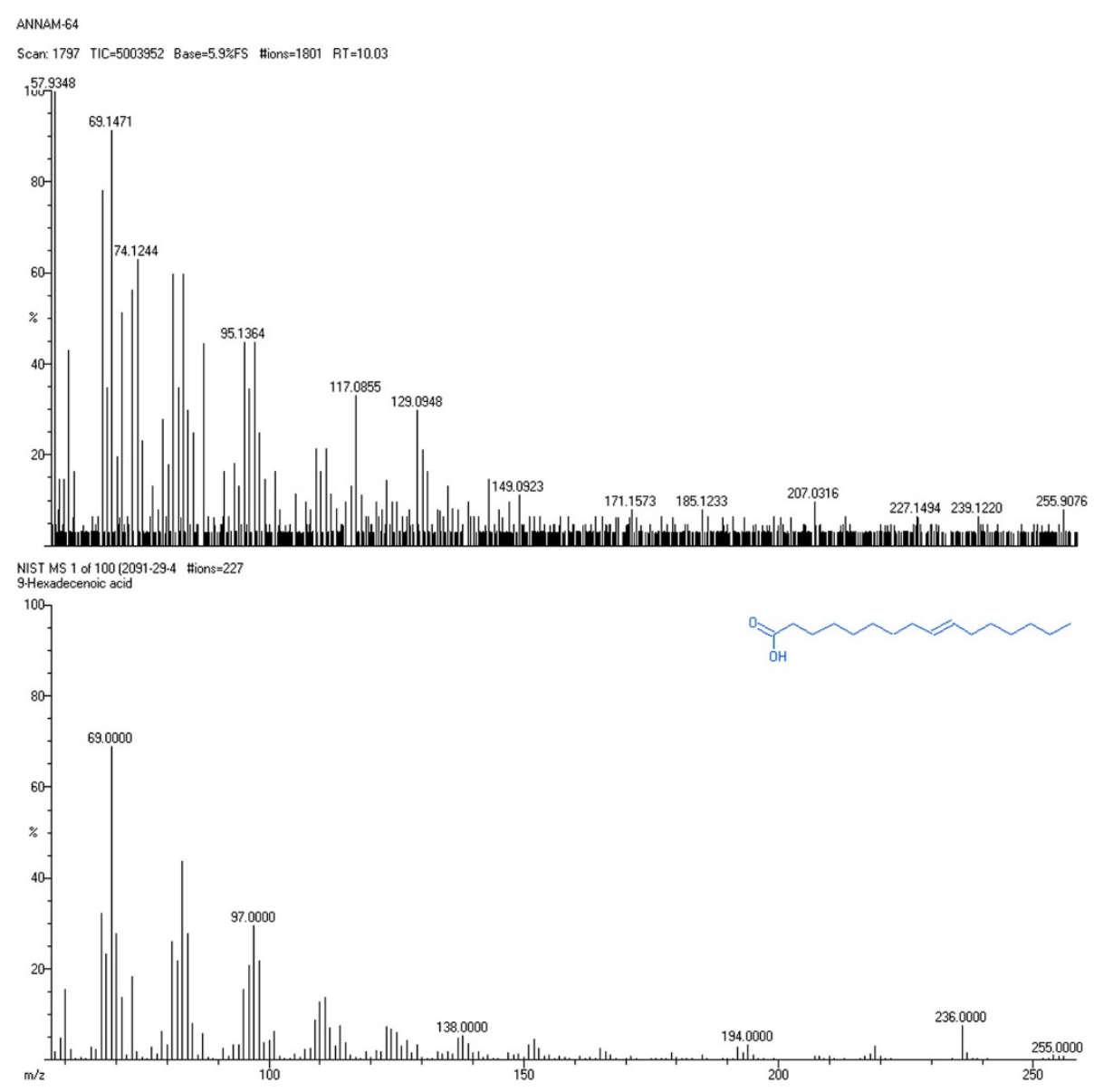

Figure 1 GC-MS of isolated fraction Dv-1.

\section{Statistical analysis}

Data are expressed as mean \pm SEM. Statistical analysis was performed by one-way analysis of variance (ANO VA). The least significant difference test was used for mean comparisons and $p<0.05$ was considered to be statistically significant.

\section{Results}

\section{Acute toxicity study}

Acute toxicity study showed that various extracts of Dregea volubilis did not produce any toxic symptoms when administered orally to rats. The lethal dose $\left(\mathrm{LD}_{50}\right.$ value) was of $2000 \mathrm{mg} / \mathrm{kg}$ body weight.

Effect of different leaf extracts of Dregea volubilis on FBG of normal and diabetic rats

Various extracts of Dregea volubilis (200 mg/kg) were evaluated in normal and diabetic rats along with the standard drug Metformin (50 mg/kg). In normal and diabetic rats, among all the extracts, ethanolic extract of Dregea volubilis reduced plasma glucose concentration

Table 3 Effect of oral administration of isolated fraction (DV-1) on plasma glucose concentration, cholesterol, triglyceride, and HDL for 21 days

\begin{tabular}{|c|c|c|c|c|c|c|}
\hline \multirow[t]{2}{*}{ Treatment } & \multicolumn{3}{|c|}{ Fasting plasma glucose (mg/dl) } & \multirow{2}{*}{$\begin{array}{l}\text { Cholesterol } \\
\text { (mg/dl) }\end{array}$} & \multirow{2}{*}{$\begin{array}{l}\text { Triglyceride } \\
\text { (mg/dl) }\end{array}$} & \multirow{2}{*}{$\begin{array}{c}\mathrm{HDL} \\
(\mathrm{mg} / \mathrm{dl})\end{array}$} \\
\hline & 0 day & 10 day & 21 day & & & \\
\hline Normal control & $64.8 \pm 7.9$ & $91.9 \pm 3.2$ & $89.3 \pm 6.9$ & $93.6 \pm 4.3$ & $71.6 \pm 5.6$ & $42.2 \pm 1.9$ \\
\hline Diabetes alone & $249.7 \pm 4.8$ & $207.6 \pm 8.5$ & $195.7 \pm 5.4$ & $84.5 \pm 3.4$ & $110.6 \pm 7.8$ & $40.3 \pm 2.1$ \\
\hline Diabetes + DV-1 (100 mg/kg) & $252.6 \pm 4.1$ & $186.3 \pm 2.5^{*}$ & $161.2 \pm 7.1^{*}$ & $87.6 \pm 2.6$ & $64.6 \pm 7.5^{*}$ & $46.7 \pm 2.3^{*}$ \\
\hline Diabetes + Metformin (50 mg/kg) & $243.6 \pm 2.8$ & $178.8 \pm 4.5^{*}$ & $156.8 \pm 6.8^{*}$ & $84.3 \pm 4.8$ & $95.6 \pm 5.6$ & $47.6 \pm 1.3^{*}$ \\
\hline
\end{tabular}

Data are expressed as mean \pm SEM. $n=6$ rats per group. ${ }^{*} p<0.05$, compared to diabetic control group. 
significantly $(p<0.05)$ as like Metformin which was summarized in Tables 1 and 2.

\section{Identification of isolated fraction and dose fixing}

Dv-1 was found to be the active principle of Dregea volubilis leaf. GC-MS confirmed the complete structure of Dv-1 and identified to be palmitic acid (Hexadecenoic acid) which was shown in Figure 1. Acute toxicity study revealed that Dv-1 did not produce any toxic symptoms when administered orally to rats. The lethal dose $\left(\mathrm{LD}_{50}\right.$ value) was of $1000 \mathrm{mg} / \mathrm{kg}$ body weight.

Effect of Dv-1 on FBG and the lipid profile of diabetic rats Dv-1 produced significant $(p<0.05)$ reduction in FBG as like Metformin in diabetic rats summarized in Table 3. Additionally Dv-1 also caused significant $(p<0.05)$ reduction in the level of triglyceride and significant $(p<$ 0.05) improvement in HDL. The effect was not much with cholesterol level.

\section{Discussion}

Administration of streptozotocin caused rapid destruction of pancreatic cells in rats, which led to impaired glucose-stimulated insulin release and insulin resistance, both of which are marked feature of diabetes. The blood glucose-lowering effect of plant extracts is generally dependent upon the degree of pancreatic $\beta$ cell destruction and useful in moderate streptozotocin-induced diabetes (Jianfeng et al. 2012). In general, an increase in blood glucose level is usually accompanied by an increase in plasma cholesterol, triglyceride, LDL levels and a decrease in HDL level as observed in diabetic patients (Henry et al. 2005). The marked hyperlipidemia (increase in the level of lipid in the body) that characterizes the diabetic state may be the consequence of the uninhibited actions of lipolytic hormones on fat depots (Saha et al. 2012). Among all the extracts tested, the ethanol extract produced significant reduction in the blood glucose level comparable to that of Metformin treatment. Isolated fraction $\mathrm{Dv}-1$ was confirmed as hexadecenoic acid by gas chromatography, the compound peak being observed at 10.03 retention time. Further mass spectrum was performed to confirm structure of the compound. Hexadecenoic acid is a metabolite of the saturated fatty acid of palmitic acid that has been hydroxylated on its terminal $(\dot{\omega})$ carbon. This $\dot{\omega}$ - hydroxylation of palmitic acid occurred by cytochrome P-450 in both plants and animals (Roman et al. 1993). Palmitic acid (Hexadecenoic acid) lowers blood glucose and alters the lipid profile (decreases TGL, cholesterol and improves HDL). Several investigators, however recognized that palmitic acid acutely stimulates glucose uptake via activated protein kinase and extracellular signal-related kinase (Jing et al. 2011) and produced great improve- ment of the altered lipid profile, it may also participates in the hypolipidemic activity by inactivating hepatic HMG-CoA reductase a key enzyme, in cholesterol synthesis. The improvements in the lipid profile in diabetic animals after treatment with palmitic acid (Hexadecenoic acid) could be beneficial in preventing diabetic complications. With the research carried out, hexadecenoic acid from the ethanolic extract of Dregea volubilis leaf has shown significant reduction in blood glucose and alteration in the lipid profile in diabetic rats.

\section{Competing interests}

The authors declare that they have no competing interest.

\section{Authors' contributions}

VN participated in study design, collection of data and performed the data analysis. AS participated in drafting the article and both authors read and approved the final manuscript.

\section{Acknowledgements}

Authors are thankful to Indian Institute of Technology, Chennai where GC MS spectrum analysis was performed.

Received: 8 April 2013 Accepted: 12 August 2013

Published: 21 August 2013

\section{References}

Aikinson MA, Maclaren NK (1994) The pathogenesis of insulin dependent diabetes. N Engl J Med 331:1428-1436

De-Fronzo RA, Bonadonna RC, Ferrannini E (1997) Pathogenesis of NIDDM. In: International Text book of Diabetes mellitus, 2nd edn. Chichester, John Wiley, England, pp 635-712

Donath MY, Ehses JA (2006) Type I and type || diabetes: NOD the diabetes we thought it was. Proc Natl Acad Sci 103:12217-12218

Grover JK, Yadav SP (2004) Pharmacological actions and potential uses of Momordica charantia: a review. J Ethnopharmacol 93:123-132

Hansotia T, Drucker DJ (2005) GIP and GLP-1 as incretin hormones: lessons from single and double incretin receptor knockout mice. Regul Pept 128:125-134

Heber MF, Ferreira SR, Velez LM (2013) Prenatal hyperandrogenism and lipid profile during different age stages: an experimental study. Fertil Steril 99 (2):551-557

Henry NG, Yuan-Li Z, Antonio H (2005) Regulation of plasma triglycerides in insulin resistance and diabetes. Arch Med Res 36:232-240

Jain AK, Mohan G, Vairale RS (2010) Folklore claims on some medicinal plants used by Bheel tribe. Ind J Tradit Knowl 9(1):105-107

Jianfeng C, Chaopin L, Pengying Z (2012) Anti diabetic effect of burdock (Arctium lappa L.) root ethanolic extract on streptozotocin-induced diabetic rats. African J Biotech 11(37):9079-9085

Jing P, Gong P, Linghai L (2011) Palmitic acid acutely stimulates glucose uptake via activation of Akt and ERK1/2 in skeletal muscle cells. J Lipid Res 52 (7):1319-1327

Kahn CR, Shechter Y (1991) Insulin oral hypoglycemic agents and the pharmacology of the endocrine pancreas in the pharmacological basis of therapeutics. In: Gillman AG, Rail TW, Nies AS, Taylor P (eds) Insulin oral hypoglycemic agents and the pharmacology of the endocrine pancreas in the pharmacological basis of therapeutics. Pergamon press, New York, pp 1463-1495

Kavishankar N, Lakshmidevi S, Mahadeva Murthy HS (2011) Diabetes and medicinal plants-a review. Int J Pharm Biomed Sci 2(3):65-80

King H, Aubert RE, Herman WH (1998) Global burden of diabetes 1995-2025: prevalence, numerical estimates, and projection. Diabetes Care 21:1414-1431

Masana L, Ibarretxe D, Heras M (2012) Substituting non-HDL cholesterol with LDL as a guide for lipid-lowering therapy increases the number of patients with indication for therapy. Atherosclerosis 226(2):471-475

Pandikumar P, Ayyanar M, Ignacimuthu S (2007) Medicinal plants used by Malasar tribes of Coimbatore district, Tamil Nadu. Indian J Trad Knowledge 6:579-582 
Pepato MT, Mori DM, Baviera AM (2005) Fruit of the jambolan tree (Eugenia jambolana) and experimental diabetes. J Ethnopharmacol 96:43-48

Rajadurai M, Vidhya VG, Ramya M (2009) Ethno-medicinal plants used by the traditional healers of Pacchamalai hills, Tamil Nadu, India. J Ethnobiol Ethnomed 3:39-41

Roman L, Palmer CNA, Clark JE (1993) Expression of rabbit cytochromes P-450 which catalyze the $\dot{\omega}$-hydroxylation of arachidonic acid, fatty acid and prostaglandins. Arch Biochem Biophys 307(1):57-65

Saha HR, Sarkar BC, Khan SA, Sana NK, Choudhury S (2012) A comparative study of thyroid hormone and lipid status in diabetic and non diabetic adults. Open Access Sci Reports 1(9):1-5

Silija VP, SamithaVarma K, Mohanan KV (2008) Ethnomedicinal plant knowledge of the Mullukuruma tribe of Wayanad district, Kerala. Indian J Trad Knowledge 7:612-614

Sriplang K, Adisakwattana K, Rungsipipat K, Yibchok-anun K (2007) Effects of Orthosiphon stamineus aqueous extract on plasma glucose concentration and lipid profile in normal and streptozotocin-induced diabetic rats. J Ethnopharmacol 109:510-514

Takeshi K, Shoichi N, Yasunori K (2002) Report of the committee on the classification and diagnostic criteria of diabetes mellitus. Diabetes Res Clin Pract 55:65-85

Tripathi J, Kumari R, Vrish Dhwaj A (2012) Anti-diabetic activity of Diplocyclos palmatus Linn. in Streptozotocin-induced diabetic mice. Ind J Pharm Edu Res 46(4):352-359

doi:10.1186/2193-1801-2-394

Cite this article as: Natarajan and Arul Gnana Dhas: Effect of active fraction isolated from the leaf extract of Dregea volubilis [Linn.] Benth. on plasma glucose concentration and lipid profile in streptozotocininduced diabetic rats. SpringerPlus 2013 2:394.

\section{Submit your manuscript to a SpringerOpen ${ }^{\circ}$ journal and benefit from:}

- Convenient online submission

- Rigorous peer review

- Immediate publication on acceptance

- Open access: articles freely available online

- High visibility within the field

- Retaining the copyright to your article

Submit your next manuscript at $\gg$ springeropen.com 